\title{
Balloon-assisted insertion of a cholangioscope into the common bile duct: a novel technique
}

The feasibility of the application of an ultrathin endoscope in direct cholangioscopy and endoscopic retrograde cholangiopancreatography has been reported recently $[1-4]$. However, difficulties are occasionally encountered when inserting a scope into the common bile duct because the scope is sometimes pushed too far downward in the duodenum ( $\bullet$ Fig. 1 a,b). We report here a novel technique of balloon-assisted insertion of an ultrathin scope into the common bile duct.

Two large stones with diameters of around $3 \mathrm{~cm}$ were found in the dilated common bile duct of an 89-year-old man with epigastric pain and jaundice. Unfortunately, we failed to remove all the stones by mechanical lithotripsy using a standard side-viewing duodenoscope because some of the fragmented stones were impacted deep in the common bile duct, and they could not be removed using a basket or extraction balloon catheter under fluoroscopic guidance. We also failed to reach the remaining stones with an ultrathin forward-viewing endoscope (EG530N5; Fujinon-Toshiba, Tokyo, Japan) using a guide wire, as described by Larghi \& Waxman [1]. We therefore placed a duodenal balloon (a 30-mL balloon catheter; Top Corp., Tokyo, Japan) as a fulcrum to make insertion of the endoscope easier ( $\mathbf{F i g .} \mathbf{1} \mathbf{c}, \mathbf{d}$ and $\mathbf{2} \mathbf{a}, \mathbf{b}$ ). This technique made deep insertion of the scope possible and we successfully removed all the stones using a basket catheter under direct cholangioscopy (๑ Fig. 2 c, d).

To our knowledge, this is the first report on duodenal balloon-assisted insertion of a cholangioscope. Another cholangioscopic technique that uses a "babyscope" has been described but this is expensive and cumbersome, and is not suitable for lithotripsy because of the limited number

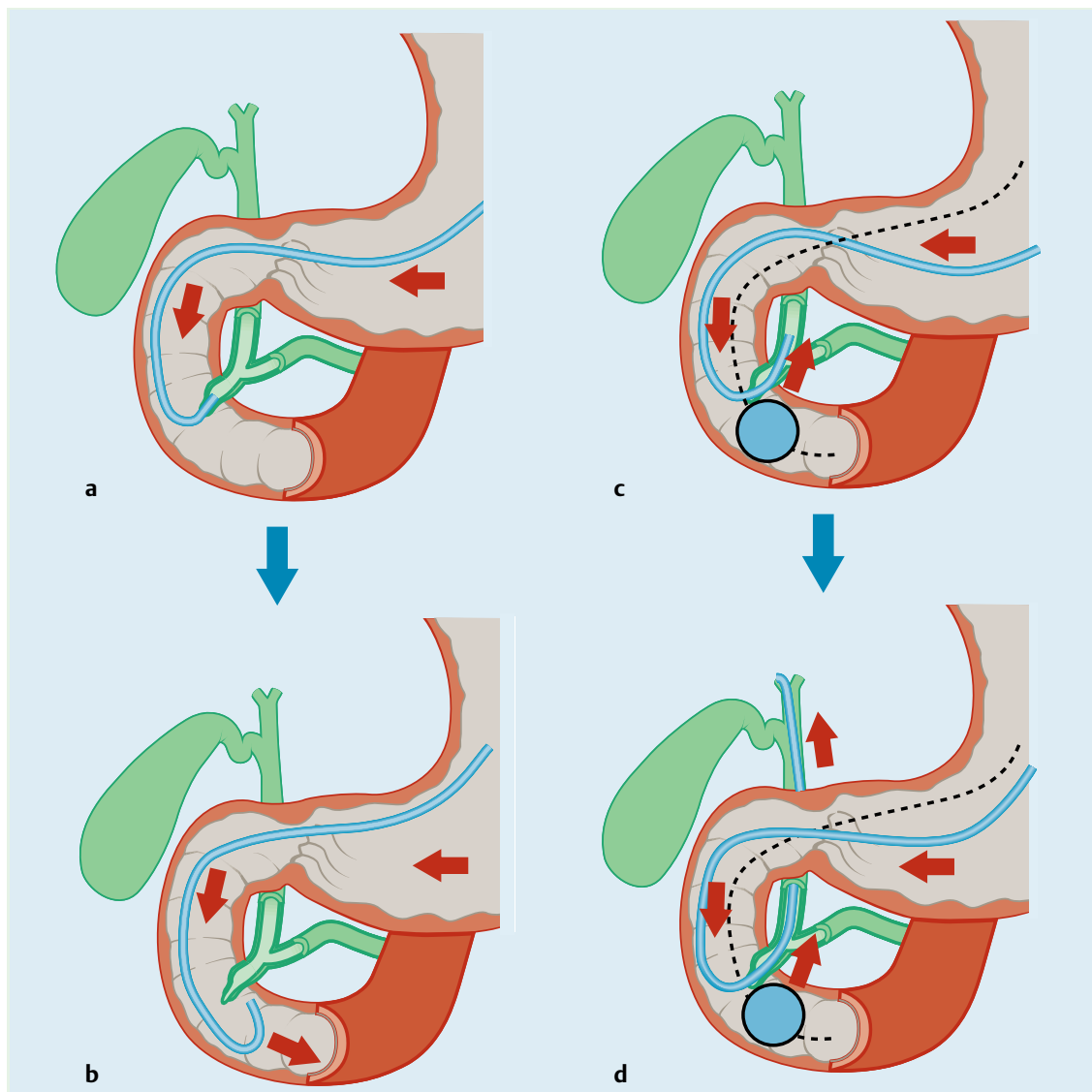

Fig. 1 Balloon-assisted insertion of a cholangioscope into the common bile duct. The endoscope is occasionally pushed downward in the duodenum (a), resulting in failure to insert it into the common bile duct (b). By placing a duodenal balloon as a fulcrum (c), a scope is easily inserted deep into the common bile duct (d).

of channels. Moreover, insertion of an endoscope using a guide wire [1] does not always work, as in the present case. We overcame these difficulties by using a duodenal balloon as a crosstie, avoiding the need for a guide wire. Our method is easy to perform and so could be widely applied in direct cholangioscopy.

Endoscopy_UCTN_Code_TTT_1AR_2AJ

\section{A. Mori, H. Tatebe, N. Ohashi, T. Maruyama, K. Sakai, T. Shibuya, M. Okuno}

Department of Gastroenterology, Inuyama Chuo Hospital, Inuyama, Aichi, Japan 

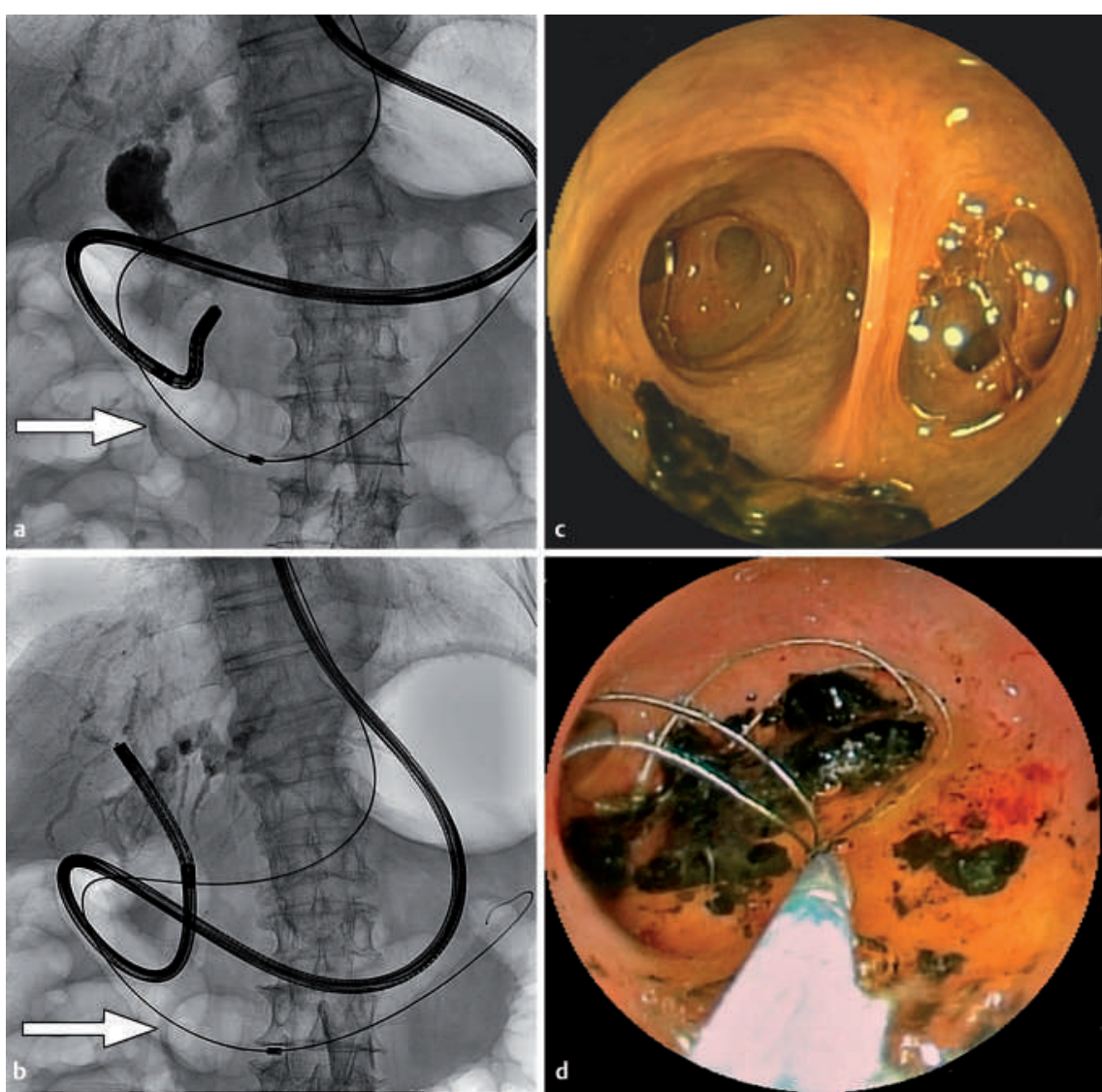

Fig. 2 Lithotripsy of common bile duct stones under balloon-assisted direct cholangioscopy, using an ultrathin scope. Fluoroscopic images showing insertion of the scope into the common bile duct $(\mathbf{a}, \mathbf{b})$, the arrows indicating the duodenal balloon. Cholangioscopic views of the fragmented stones at the biliary bifurcation (c) and of the stones being removed using a basket catheter (d).

\section{References}

1 Larghi A, Waxman I. Endoscopic direct cholangioscopy by using an ultra-slim upper endoscope: a feasibility study. Gastrointest Endosc 2006; 63: 853-857

2 Mori A, Sakai K, Ohashi $N$ et al. Electrohydraulic lithotripsy of the common bile duct stone under transnasal direct cholangioscopy. Endoscopy DOI: 10.1055/s-2007-995446

3 Mori A, Asano T, Maruyama Tet al. Transnasal ERCP/ENBD using an ultrathin esophagogastroduodenoscope. J Gastroenterol 2006; 41: $1237-1238$

4 Mori A, Ohashi N, Maruyama T et al. Endoscopic retrograde cholangiopancreatography through gastric stoma using ultrathin endoscope: a novel approach. Endoscopy DOI: $10.1055 / \mathrm{s}-2007-966804$

Bibliography

DOI 10.1055/s-2007-995402

Endoscopy 2008; 40: E106-E107

(c) Georg Thieme Verlag KG Stuttgart · New York . ISSN 0013-726X

\section{Corresponding author}

\section{A. Mori, MD}

Department of Gastroenterology

Inuyama Chuo Hospital

Inuyama 484-8511

Aichi

Japan

Fax: +81-568-62-8761

a-mori@inuyamachuohospital.or.jp 